\title{
P.086 Herb and spice mediated interactions in oncologic patients treated with chemotherapy
}

FRANCESCA TURCO, ANDREA ELIO SPRIO, ILENIA BERTAGGIA, TIZIANA ARMANDO, SILVANA STORTO, SARAH ALLEGRA, SILVIA DE FRANCIA*, MARIA VALENTINA MUSSA

*DEPARTMENT OF BIOLOGICAL AND CLINICAL SCIENCES, UNIVERSITY OF TURIN, S. LUIGI GONZAGA HOSPITAL, ORBASSANO (TO), ITALY
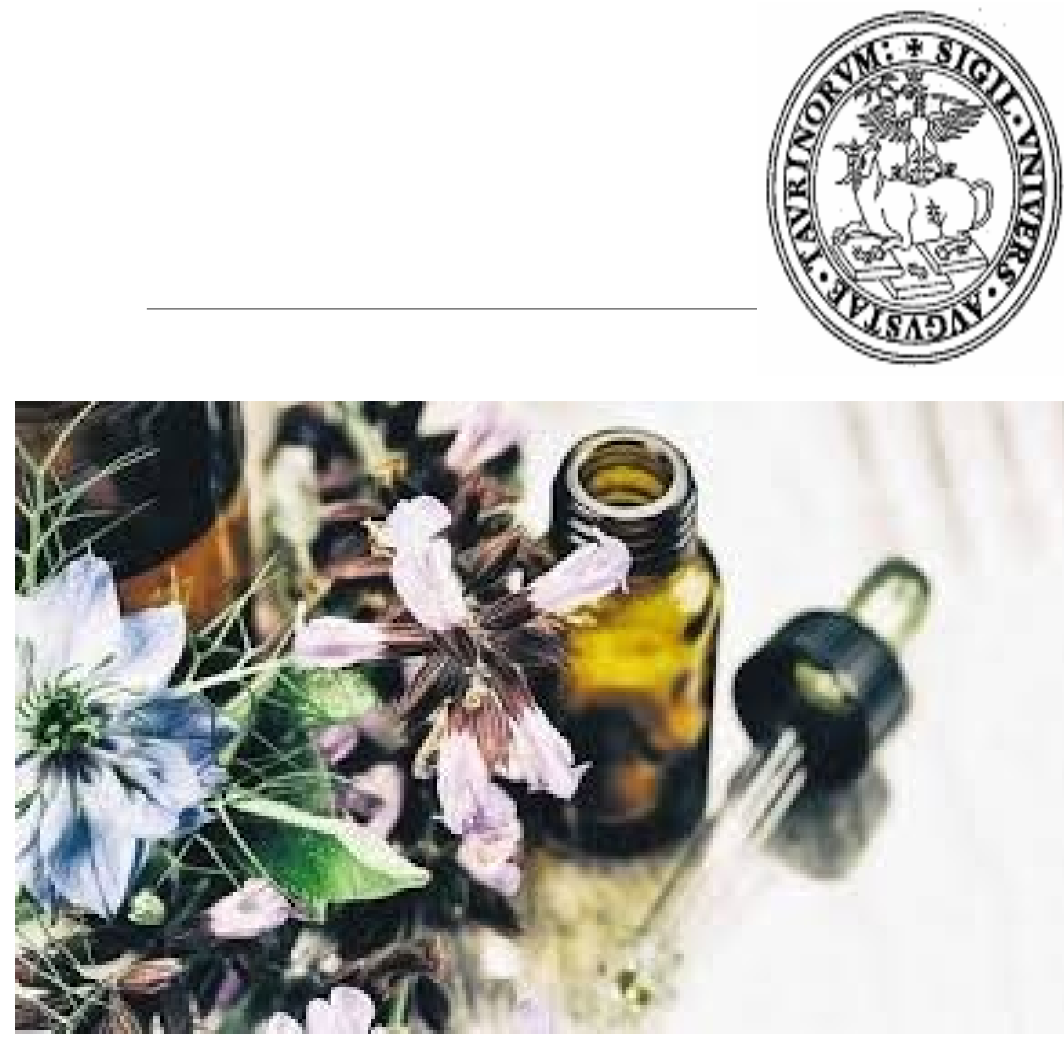

Dott. Silvia De Francia e-mail: silvia.defrancia@unito.it 


\section{BACKGROUND}

The use of herbs to treat illnesses was common in all historical eras.

Furthermore, many "modern" drugs have "natural" origins, and this point of view is pursued and stressed for commercial purposes in

any fields of treatment. A plethora of dietary supplements, phytotherapeutics and homeopathic substances are nowadays easy to buy and, for this reason, the thought that natural is equal to safe is

becoming widespread among the population. Anyhow, all the substances we take herbs or food, are drugs and thus could cause adverse effects as direct toxicity (e.g. use of foxglove, even a rare

case of belladonna berries misidentified as juniper berries) or

interaction with other substances. In the latter case, many foods, herbs and spices have already proved to alter co-administered drugs pharmacokinetics and/or pharmacodynamics. The results range from a reduced drug activity to the onset of drug-mediated side effects, thus potentially hampering the efficacy of pharmacological therapy.

\section{Here, we focus on the possible onset of gastrointestinal side effects induced by foods and dietary supplements in a} population of oncologic patients, treated with chemotherapy in day hospital regimen.

\section{MATERIALS AND METHODS}

We enrolled 318 patients at the Oncology Unit of Molinette Hospital (Turin, Italy) between March 2016 and September 2017. The inclusion criteria were the desire to participate the study and the therapeutic

regimen adherence. Patients were interviewed to investigate consumption of eucalyptus, sage, broccoli, grapefruit, echinacea, mint, garlic, pomegranate, licorice, oats, pineapple, chamomile, soy,

vinegar, hypericum, ginger, valerian, tobacco, ginkgo, ginseng, propolis, turmeric, aloe. Moreover, patients were asked if they suffered of gastrointestinal side effects over the last month. 
Three hundred and two (95\%) of the enrolled patients consumed at least one of considered foods/dietary supplements and among them, $254(80 \%)$ reported one or more gastrointestinal side effects.

The most commonly used substances were garlic (62\%) and vinegar $(61 \%)$, both occasionally for food purpose. Otherwise, ginger $(31 \%)$ and aloe $(17 \%)$ were assumed mainly for better tolerate chemotherapy.

Among side effects, the most reported were nausea (50\%) and dysgeusia (48\%). Significant correlations were detected between the use of ginger and the onset of emesis $(p<0.05)$.

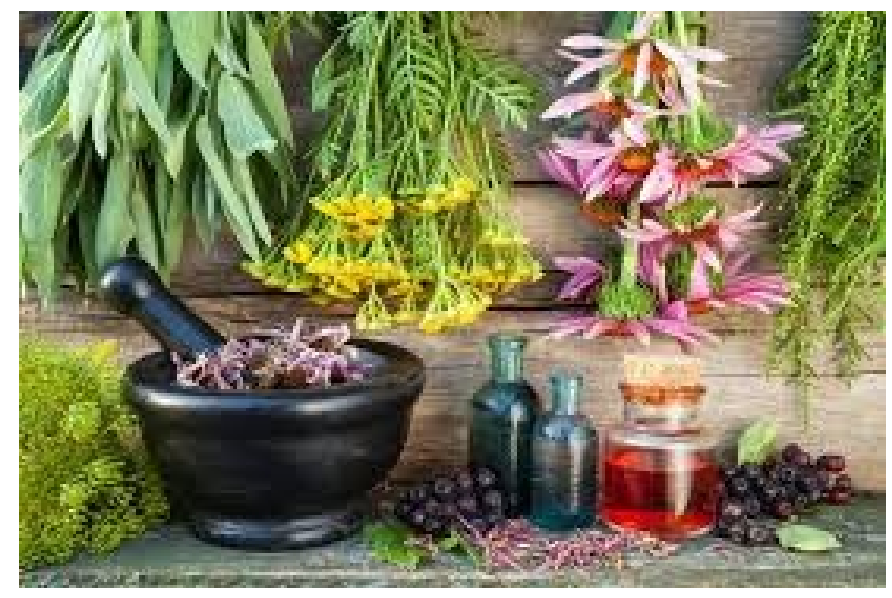

DISCUSSION AND CONCLUSION

Emesis is a common side effect after chemotherapy, thus oncologic patients are often co-administered with antiemetic drugs as metoclopramide. It is mainly metabolized by CYP2D6 and in a lesser extent by CYP3A4 which are also targets of gingerols; despite 8- and 10-gingerol inhibited CYPs, 6-gingerol was demonstrated to induce the expression of CYP3A4. In this point of view, the intake of ginger, to better tolerate the treatment, could influence the activity of metoclopramide in preventing the emetic symptoms in oncologic patients undergoing chemotherapy. 